\title{
How to Tackle Key Challenges in the Promotion of Physical Activity among Older Adults (65+): The AEQUIPA Network Approach
}

\author{
Sarah Forberger ${ }^{1, *, \dagger}$, Karin Bammann ${ }^{2,+}$, Jürgen Bauer ${ }^{3, \dagger}{ }^{\dagger}$, Susanne Boll ${ }^{4, \dagger}$, Gabriele Bolte ${ }^{5,6, \dagger}$, \\ Tilman Brand ${ }^{1,+}{ }^{,}$, Andreas Hein ${ }^{7,+}$, Frauke Koppelin ${ }^{8,+}$, Sonia Lippke ${ }^{9,+}$, Jochen Meyer ${ }^{10,+}$, \\ Claudia R. Pischke ${ }^{1,+}$, Claudia Voelcker-Rehage ${ }^{11,+}$ and Hajo Zeeb ${ }^{1,6,+}$ \\ 1 Leibniz Institute for Prevention Research and Epidemiology_BIPS, 28359 Bremen, Germany; \\ brand@leibniz-bips.de (T.B.); pischke@leibniz-bips.de (C.R.P.); zeeb@leibniz-bips.de (H.Z.) \\ 2 Working Group Epidemiology of Demographic Change, Institute for Public Health und Nursing \\ Research (IPP), Faculty for Human and Health Sciences, University of Bremen, 28359 Bremen, Germany; \\ bammann@uni-bremen.de \\ 3 Geriatrisches Zentrum, Universität Heidelberg, Agaplesion Bethanien-Krankenhaus, \\ 69126 Heidelberg, Germany; juergen.bauer@bethanien-heidelberg.de \\ 4 Media Informatics and Multimedia Systems, Department of Computing Science, Carl von Ossietzky \\ University of Oldenburg, 26121 Oldenburg, Germany; Susanne.Boll@informatik.uni-oldenburg.de \\ 5 Department of Social Epidemiology, Institute for Public Health and Nursing Research, University of Bremen, \\ 28359 Bremen, Germany; gabriele.bolte@uni-bremen.de \\ 6 Research Focus Health Sciences Bremen, University of Bremen, 28359 Bremen, Germany \\ 7 Department of Health Services Research, School of Medicine and Health Sciences, Carl von Ossietzky \\ University of Oldenburg, 26111 Oldenburg, Germany; andreas.hein@uni-oldenburg.de \\ 8 Section Technology and Health for Humans, Jade University of Applied Sciences Oldenburg, \\ 26121 Oldenburg, Germany; frauke.koppelin@jade-hs.de \\ 9 Department of Psychology and Methods, Jacobs University Bremen, 28759 Bremen, Germany; \\ s.lippke@jacobs-university.de \\ 10 OFFIS-Institute for Information Technology, 26121 Oldenburg, Germany; jochen.meyer@offis.de \\ 11 Institute of Human Movement Science and Health, Faculty of Behavioral and Social Sciences, Chemnitz \\ University of Technology, 09107 Chemnitz, Germany; claudia.voelcker-rehage@hsw.tu-chemnitz.de \\ * Correspondence: forberger@leibniz-bips.de; Tel.: +49-(0)421-218-56900 \\ + AEQUIPA Consortium.
}

Academic Editor: Li Ming Wen

Received: 1 February 2017; Accepted: 27 March 2017; Published: 4 April 2017

\begin{abstract}
The paper introduces the theoretical framework and methods/instruments used by the Physical Activity and Health Equity: Primary Prevention for Healthy Ageing (AEQUIPA) prevention research network as an interdisciplinary approach to tackle key challenges in the promotion of physical activity among older people (65+). Drawing on the social-ecological model, the AEQUIPA network developed an interdisciplinary methodological design including quantitative/qualitative studies and systematic reviews, while combining expertise from diverse fields: public health, psychology, urban planning, sports sciences, health technology and geriatrics. AEQUIPA tackles key challenges when promoting physical activity (PA) in older adults: tailoring of interventions, fostering community readiness and participation, strengthening intersectoral collaboration, using new technological devices and evaluating intervention generated inequalities. AEQUIPA aims to strengthen the evidence base for age-specific preventive PA interventions and to yield new insights into the explanatory power of individual and contextual factors. Currently, the empirical work is still underway. First experiences indicate that the network has achieved a strong regional linkage with communities, local stakeholders and individuals. However, involving inactive persons and individuals from minority groups remained challenging. A review of existing PA intervention studies among the elderly revealed the potential to assess equity effects. The results will add to the theoretical
\end{abstract}


and methodological discussion on evidence-based age-specific PA interventions and will contribute to the discussion about European and national health targets.

Keywords: ageing; ageing research; older adults; physical activity

\section{Introduction}

Healthy ageing is one of the great challenges of the 21st century. By 2030 , approximately $25 \%-30 \%$ of the population in the European Union (EU 27) will be 65 years and older [1,2]. Physical activity (PA) plays a major role in healthy ageing and is important for physical and mental health, well-being, quality of life, development of personal resources, social contacts and maintenance of independent living [3]. Physical inactivity has been identified as the fourth leading risk factor for global mortality [4]. It has major implications for the prevalence of numerous non-communicable diseases such as cardiovascular diseases, diabetes and cancer as well as their associated risk factors such as elevated blood pressure and blood glucose levels and overweight [5].

The World Health Organization (WHO) recommends at least 150 min of moderate-intensity aerobic PA or at least 75 min of vigorous-intensity aerobic PA throughout the week for persons aged 65 and above to prevent non-communicable diseases [5]. Further, for this age group, flexibility and strength training is recommended for at least two times per week. This training increases mobility skills and decreases the risk of falling [6,7]. Moderate training, for example outdoor walking, improves cardio-metabolic markers [8], resting blood pressure [9] and postprandial blood glucose response [10]. Reductions in body mass index and blood pressure lower the risk of type II diabetes mellitus and, through a variety of mechanisms, cardiovascular mortality risk [11]. Additionally, positive effects of exercise on mental health and cognition have been reported [12]. Conversely, age-associated chronic diseases, such as osteoarthritis and osteoporosis, and falls may strongly impair an individual's ability to be physically active and lead to an accelerated loss of muscle mass (sarcopenia) in older age [13-15]. However, health benefits of exercise are not only restricted to healthy persons. They are also evident in the secondary and tertiary prevention of chronic diseases [16]. Although the beneficial effects of PA are well established, PA levels in the population at large and in the elderly are below WHO recommendations. Data from the national representative German Health Interview and Examination Survey for Adults (DEGS) show that $83.2 \%$ of women and $80.7 \%$ of men aged $60-69$ are physically active for less than $150 \mathrm{~min}$ per week [17]. Therefore, it is of importance to increase PA levels among people aged 65 and above. Older adults vary considerably in their abilities, needs and motivations for PA due to differences in their biographical experiences, social circumstances and health status [18-20]. While the functional status declines with age, there is large dispersion in the physical fitness and differences in the speed of decline in older adults [21,22]. In AQUIPA, we focus on PA as contributor to primary prevention among healthy community-dwelling older adults.

The paper provides the rationale and study design of the Physical Activity and Health Equity: Primary Prevention for Healthy Ageing (AEQUIPA, http://www.aequipa.de) prevention research network. AEQUIPA aims to increase PA among older adults by addressing key challenges of population-based PA promotion, namely: (1) tailoring PA interventions to individual conditions (e.g., on basis of the Health Action Process (HAPA) model) [23]; (2) fostering community readiness and participation; (3) strengthening intersectoral collaboration; (4) using technological devices and (5) evaluating intervention generated inequalities. With its approach, AEQUIPA combines various disciplines and experts to tackle key challenges in the promotion of PA among older adults from various angles so as to improve the knowledge about theory and methods development, tailoring of intervention, technic use, and the role of intervention generated inequality and environmental factors. After completion of the various subprojects at the end of 2017, the results gained will be translated into 
guidance for policy makers and practitioners on how to tackle physical inactivity in persons over 65 years as well as how to create healthy living environments.

\subsection{Key Challenges Influencing the Initiation and Maintenance of PA}

According to Sallis and colleagues' socio-ecological model [24], factors and conditions at multiple levels influence PA behaviour as individual characteristics (e.g., cognition, objective and subjective health, health-related behaviour, self-perception, planning, intention, PA level) and contextual factors (environment, setting, living and social condition) significantly affect and modify ageing processes in later life. Further, the use of new technologies can have a positive influence on PA levels. This is however affected by individual characteristics such as openness and technical affinity, and also factors such as socio-economic status and access to information and resources. Although PA intervention can also increase or reduce inequality, these aspects are rarely considered during the intervention development and implementation process. The AEQUIPA framework provides a combined approach to these aspects and aims for transdisciplinary and integrative research guided by the socio-ecological model.

\subsubsection{Tailoring PA Interventions to Individual Conditions}

PA interventions seem to be effective if they target the essential factors relevant to the self-regulation of individuals [25]. Positive health effects of PA are already evident after six to twelve weeks of training with two to three sessions per week [26]. However, a key question is how these interventions should be designed and tailored to meet the needs of older adults and their ability to engage in PA, and to support behaviour change in the long term. Few data are available on adherence to PA programs among older persons and on tailoring such programs to improve long-term adherence. Personal characteristics, such as age, gender, cultural background, norms, beliefs and health literacy need to be taken into account when designing PA interventions for older adults. Further, social-cognitive variables, in particular self-efficacy, outcome expectations and social support are important for PA initiation and maintenance [27]. In addition, the fear of falling can hamper PA while on the other hand exercises can reduce an individual's fear of falling [7]. Gender is an important stratifying category in terms of needs, access, targeting and uptake of preventive interventions and should be considered during planning, in the process steps as well as in the evaluation of interventions [28].

\subsubsection{Fostering Community Readiness and Participation}

Community factors such as capacity building and community involvement are often recommended as key factors to improve equitable access to prevention and health promotion. A systematic review by Stith et al. concluded that four conditions are essential for the successful implementation of a preventive intervention in a community: (i) there is sufficient community capacity, i.e., a functioning community coalition is in place; (ii) the community recognizes a problem and existing programs cannot solve it sufficiently; (iii) a key person/organization is identified; and (iv) there is an appropriate climate for the implementation, i.e., stakeholders will benefit from participation or there will at least be no disadvantages for them, and participation will not be deemed to be too costly [29]. It is therefore recommended to assess and, if necessary, increase community readiness before starting an intervention [29]. Participatory models of intervention development, such as the PRECEDE-PROCEED planning model [30], have been proposed for setting up health promotion programmes that fit to local contexts.

\subsubsection{Strengthening Intersectoral Collaboration}

The built environment has a crucial impact on PA in terms of accessibility to green spaces and the option to use public urban space, as well as the provision of social infrastructure and local supply [31]. A community environment that favours PA may even produce additional health benefits such as good 
mental health and injury prevention [32]. In older adults, the neighbourhood environment influences functional health and quality of life. Older people are more likely to be physically active outside in neighbourhoods with high walkability, interconnected street layouts, smooth footways, local services and facilities, and green spaces [33].

The built environment includes urban design, transportation systems and land-use planning. The promotion of PA by urban planners may occur through the consideration of population density, diversity of land use and street connectivity. Though there is multifaceted evidence on the effectiveness of urban environment interventions on PA, this evidence is limited as most studies were conducted in dense, urban environments [34]. Whether the results are also applicable to small towns and cities in more rural areas remains to be determined.

In urban planning, Strategic Environmental Assessment (SEA) at the strategy, policy and programme level, and Environmental Impact Assessment (EIA) at the project level have traditionally addressed health issues. However, SEA and EIA were only two of many aspects and often with a restricted focus on bio-physical health determinants [35]. Though urban health issues are tacitly agreed upon in local planning concepts, they are not yet part of public participation procedures, nor are they implemented explicitly [34]. Moreover, concrete and manageable health impact assessment (HIA) scales, particularly in the environmental assessment, are lacking.

Along with planning aspects, factors such as housing conditions, self-perceived social support, social activity and the capability to organise one's own daily life have a crucial effect on health behaviour and PA [36]. The work of Sallis and colleagues shows that in the age group of 65 and above, the living environment and housing conditions increasingly gain importance [37]. Therefore, these factors should be considered when designing age-specific interventions to promote PA in older age.

\subsubsection{Use of New Technological Devices}

Over the last years new technological means (e.g., smart phones, tablet computers) have offered possibilities to increase opportunities for delivering and tailoring interventions. Participation in such technology-supported interventions is associated with a more active lifestyle among young adults [38]. Whether this also applies to older adults is still unclear. The European Commission recently prioritised research in this field, particularly in the area of 'healthy ageing'. One priority is research on the development of technology-based interventions for health promotion for older European adults [39].

Using the internet and smart phone applications (apps) for health promotion and for primary prevention in healthy populations are promising options for public health researchers because so called 'small changes' or 'early nudges' approaches can be easily implemented using these modalities, and large amounts of data on health behaviour can be collected [40].

Further advantages include the notion that such intervention modules are accessible and usable independent of an intervention team. Further, such application can reach segments of the population that may not get to know about traditional health promotion interventions [40]. Recent research shows that technologically-supported interventions to promote PA, e.g., using smartphones and mobile devices, may lead to increases in PA among older adults [41].

For many years technology has been used for personal health, e.g., to improve doctor-patient-relationships, for the management of chronic diseases or to support health behaviour change interventions. Smart health systems such as activity trackers, sports watches or networked scales became available only recently [42]. These systems allow the monitoring of relevant health parameters and deliver additional services through the internet. By design these are lifestyle products suitable for daily use by laypersons. Smart health systems, in conjunction with information technologies such as computers and smartphones, hold considerable potential for primary prevention [43].

Applying technology for personal health always requires an interdisciplinary approach, taking into account medical, technological and psychosocial perspectives [44]. Primary prevention places particular emphasis on these perspectives. Usability, acceptance and integration in daily life are crucial to ensure long-term compliance, and may require trade-offs on the medical effects. 
Technology can support PA interventions in various ways. Ambient or body-worn sensors allow for the monitoring and objectively quantification of activities [45]. The collected data form the basis for the assessment of the health status and for decisions about future activities. Whereas motivating and persuasive measures, social networking and gamification elements can improve users' adherence to interventions, background information on, e.g., activity levels may help users understand and master their personal health.

In order to realise the full potential of technology-based health services, users' acceptance has to be reviewed continuously as one important reason for the failure of technological products supporting individual health is a lack of understanding users' requirements [46]. Web-based or smart phone based interventions to promote PA might be more useful for 'younger' older adults ( $<80$ years of age) who tend to be more experienced in interacting with technology compared to the very old.

\subsubsection{Intervention Generated Inequalities}

There is a growing body of evidence suggesting that PA levels may be lower among socially disadvantaged population groups compared to more advantaged ones [47]. In this context, social disadvantage can relate to socio-economic (e.g., education/health literacy, income, occupation), socio-cultural (i.e., gender, ethnicity, religion) as well as socio-geographical aspects (e.g., neighbourhood deprivation, social capital). For example, previous research focusing on older adults has shown associations between low physical activity and low education, low wealth, female sex, not being white, and living in a deprived residential area [48-52]. Therefore, social inequalities in health and their determinants, such as PA, are among the main challenges in public health and health promotion, and require consideration in intervention designs.

Health promotion and prevention measures aiming to increase PA can be designed to specifically target socially disadvantaged groups. However, such targeted interventions have been shown to be difficult to implement. On the other hand, there is also evidence suggesting that non-targeted interventions, even if they are successful at improving health or health behaviours overall, may widen social inequalities by benefitting socially disadvantaged groups less [53,54]. These effects have been termed 'intervention-generated inequalities' (IGIs) and may arise at several points of intervention implementation, such as service provision, access, uptake, compliance or intervention efficacy [55]. For PA interventions, the issue of IGIs has been discussed with regard to unequal uptake and participation. However, to date only a few studies have examined whether the effectiveness of PA interventions differs between social groups [56,57]. Furthermore, the need for a greater exploration of equity impacts of interventions to promote physical activity among older adults was highlighted by a recent systematic review on interventions for adults around retirement age [58].

A recently published Cochrane review on the effectiveness of community-wide interventions aiming to increase PA underlined this knowledge gap [59]. The authors reported that none of the included studies provided results on socio-economic inequalities or other indicators of health equity thus making it impossible to analyse equity impacts.

Consequently, there is a need to design and implement interventions that also take socially disadvantaged groups into account as well as to systematically include an equity impact assessment in the evaluation of such interventions.

\section{Materials and Methods}

AEQUIPA comprises six universities and two research institutes, forming a prevention research network in North-West Germany. It combines rural and urban areas and two federal states, and merges expertise from social epidemiology, public health, psychology, urban planning, sports sciences, information technologies, health economics and geriatrics.

Social-ecological models provide a comprehensive perspective on analysing PA behaviour and are often recommended as an approach for PA interventions $[24,60]$. Drawing on this comprehensive perspective, AEQUIPA assesses factors related to PA on different ecological level, ranging from the 
intra-personal level (e.g., stages of change, technical affinity) over the perceived environment and the characteristics of the behavioural setting (e.g., community readiness) to the policy environment (urban planning). In the same way, the interventions that are developed in the AEQUIPA subprojects address the different ecological levels with some interventions focussing more on the individual level and some more on the contextual level (Table 1). Nevertheless, the comprehensive socio-ecological perspective is maintained by linking interventions addressing different levels (subproject Ready to Change (RTC) and PROMOTE) of developing a multilevel intervention in a single subproject (OUTDOOR ACTIVE). Extensive data collection will enable us to assess how factors on different ecological levels influence PA among older adults.

\subsection{Research Design}

To approach the key challenges, AEQUIPA covers five subprojects, one crosscutting project, and one $\mathrm{PhD}$ program (Figure 1). Every subproject is dedicated to its own particular research question and main focus (Table 1).

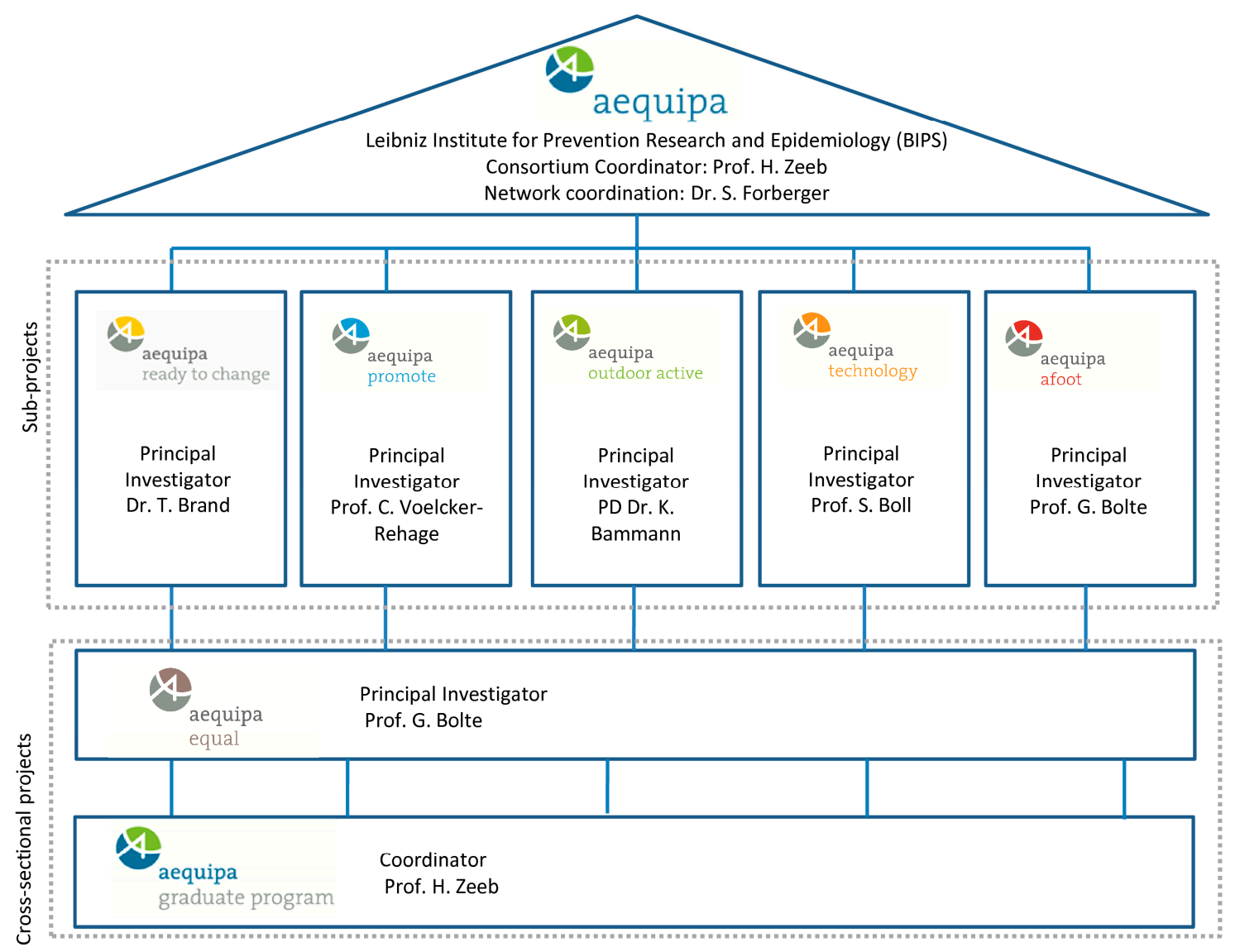

Figure 1. AEQUIPA 1 network structure. 
Table 1. Physical Activity and Health Equity (AEQUIPA) subprojects, research aim, design/methods used, envisaged sample size and main factors examined.

\begin{tabular}{|c|c|c|c|c|}
\hline Subproject Title & Research Aim & Design/Methods Used & Sample Size (Envisaged) & $\begin{array}{l}\text { Main Factors } \\
\text { Examined }\end{array}$ \\
\hline (1) RTC & $\begin{array}{l}\text { - To assess the community readiness for promoting PA among } \\
\text { older adults } \\
\text { To investigate the efficacy and cost-effectiveness of strategies to increase } \\
\text { community readiness to engage older adults in PA interventions } \\
\text { - To examine reasons for non-participation in existing PA interventions }\end{array}$ & $\begin{array}{l}\text { Community readiness } \\
\text { assessment, expert interviews }\end{array}$ & $\begin{array}{l}\text { Interviews in } n=23 \text { municipalities } \\
\text { (rural } n=12 \text {; urban } n=11 \text { ) with 5-6 } \\
\text { representatives per municipality }\end{array}$ & Contextual \\
\hline (2) PROMOTE & $\begin{array}{l}\text { - To assess the perceived community readiness for promoting PA among } \\
\text { older adults } \\
\text { To investigate the efficacy and cost-effectiveness of strategies to increase } \\
\text { community readiness to engage older adults in PA interventions } \\
\text { - To examine reasons for non-participation in existing PA interventions }\end{array}$ & Randomised controlled trial & $\begin{array}{l}\text { Older adults aged } 65-75(n=1000) \text {; } \\
\text { urban community }\end{array}$ & $\begin{array}{l}\text { Individual, } \\
\text { contextual }\end{array}$ \\
\hline $\begin{array}{l}\text { (3) OUTDOOR } \\
\text { ACTIVE }\end{array}$ & $\begin{array}{l}\text { - } \quad \begin{array}{l}\text { To assess prevalence and associations of individual and environmental } \\
\text { factors regarding outdoor PA in older adults }\end{array} \\
\text { - To identify factors predisposing, enabling and reinforcing outdoor PA } \\
\text { in older adults } \\
\text { - To develop, implement and evaluate a program for promoting } \\
\text { outdoor PA }\end{array}$ & $\begin{array}{l}\text { PRECEDE-PROCEED model, } \\
\text { complete survey in reference } \\
\text { community, round tables }\end{array}$ & $\begin{array}{l}\text { Complete survey of reference } \\
\text { community adults aged } 65-75 \\
(n=1000) ; \text { urban community }\end{array}$ & $\begin{array}{l}\text { Individual, } \\
\text { contextual }\end{array}$ \\
\hline (4) TECHNOLOGY & $\begin{array}{l}\text { - } \quad \begin{array}{l}\text { To investigate how IT-based health technologies can be used for } \\
\text { primary prevention }\end{array} \\
\text { - } \quad \text { To develop a combination of sensors to support preventive measures } \\
\text { - }\end{array}$ & $\begin{array}{l}\text { Observational and } \\
\text { intervention study }\end{array}$ & $\begin{array}{l}\text { Observational study older adults } \\
\text { aged } 65+(n=250) \\
\text { Experimental intervention study; } \\
\text { urban community }\end{array}$ & $\begin{array}{l}\text { Individual, } \\
\text { contextual }\end{array}$ \\
\hline (5) AFOOT & $\begin{array}{l}\text { - To identify local urban strategies and indicators for walkability for } \\
\text { health and equity assessment in urban planning procedures } \\
\text { To develop a guideline for intersectoral policy actions taking the } \\
\text { institutional and administrative framework of urban planning and } \\
\text { public health as well as limited communal financial resources } \\
\text { into account }\end{array}$ & $\begin{array}{l}\text { Expert interviews, simulation } \\
\text { game, round table, } \\
\text { workshops }\end{array}$ & $\begin{array}{l}\text { Expert interviews }(n=20) \\
\text { Workshops }(n=3) \text { with up to } \\
12 \text { participants } \\
\text { Simulation game }(n=2-3) \text {; } \\
\text { urban and rural communities }\end{array}$ & Contextual \\
\hline (6) EQUAL & $\begin{array}{l}\text { - To review the equity effects of PA interventions among older adults } \\
\text { - To provide guidance for the AEQUIPA subprojects on } \\
\text { inequalities-sensitive planning and implementation of interventions } \\
\text { To develop methods for an equity impact assessments of the } \\
\text { AEQUIPA interventions }\end{array}$ & $\begin{array}{l}\text { Expert interviews, systematic } \\
\text { literature review, } \\
\text { methods synthesis }\end{array}$ & Expert interviews $(n=5-10)$ & $\begin{array}{l}\text { Individual, } \\
\text { contextual }\end{array}$ \\
\hline
\end{tabular}


However, the internal structure and network approach allow a joint and mutually supportive work on the overarching research question on how to promote and maintain PA in older adults. Overall, the scientific aims of the AEQUIPA network are:

- $\quad$ To strengthen the evidence base for preventive physical activity in the context of healthy ageing in Germany, including health economic aspects (subprojects RTC, PROMOTE).

- To conduct research regarding the environmental, contextual and individual conditions enabling physical activity interventions among older adults (subprojects RTC, PROMOTE, OUTDOOR ACTIVE).

- $\quad$ To implement a strategic linkage of urban planning and public health strategies at the local level to facilitate physical activity of older adults in the context of the built environment (subproject AFOOT).

- $\quad$ To develop new approaches for understanding and monitoring the impact of physical activity interventions on health equity (subproject EQUAL).

- $\quad$ To investigate the role of new technologies in supporting physical activity among older adults (subprojects TECHNOLOGY, PROMOTE).

Where possible, a participatory approach is used within the subprojects. For example, PROMOTE uses target group involvement for the development of its preventive PA program and OUTDOOR ACTIVE applies the PRECEDE-PROCEED model to develop a community-based PA promotion program. Within TECHNOLOGY close cooperation and technic tests are used with and by the participants to analyse technic acceptance and usability.

\subsection{Measures}

AEQUIPA uses various methodological approaches und constructs/instruments (Tables 1 and 2). Within the empirical studies, persons aged 65 years and above from the German general population and who are able to engage in PA are included in the study. Persons not living independently and who are unable to engage in PA or have severe diseases such as heart attack, stroke and severe asthma are excluded. In general, a physician should be consulted beforehand. For the studies using contextual approaches persons/settings for persons older than 65 years are included/analysed. Detailed inclusion and exclusion criteria are defined by the respective subprojects [61,62]. Constructs and instruments used within the subprojects were kept compatible between the subprojects as far as possible. The methods used are questionnaires, behavioural measurements and trackers, cognitive and physical functioning tests, interviews, focus groups and simulation games. For the data collection randomised controlled trials, intervention and observational studies are being performed along with expert interviews, round tables, workshops and simulation games.

\subsubsection{Individual Characteristics}

Demographic characteristics are assessed via questionnaires covering age, gender, education, marital status and income. Socio-demographic context variables are assessed in accordance to the DEGS study. Questions regarding education are in line with the International Standard Classification of Education (ISCED).

Health risks and resources are covered by three subprojects and include potentially modifiable behavioural risk factors (e.g., dietary habits, tobacco use, alcohol consumption). Various aspects of mental health and subjective health are collected via self-administered questionnaires based on standardised instruments (Table 2).

Objective measures like weight and height are taken directly by the interviewer. Body composition (bio-impedance analysis), blood pressure (measured with an Omron 705 II (Omron, Mannheim, Germany) and waist circumference are assessed. 
Table 2. Factors, constructs and instruments / methods used within AEQUIPA sub-projects ${ }^{\text {a }}$

\begin{tabular}{|c|c|c|c|}
\hline Factor & Construct & Instrument & Data Collection Mode \\
\hline \multirow{25}{*}{ Individual } & Health & & \\
\hline & Body weight and height & Stadiometer Seca 217 (Seca, Hamburg, Germany) & $\mathrm{M} / \mathrm{T}$ \\
\hline & Obesity, body composition & $\begin{array}{l}\text { Waist circumference (Seca } 200 \text { (Seca, Hamburg, Germany)); Mid upper arm circumference (Seca 200); Skin fold } \\
\text { triceps (Harpenden Skinfold Calliper (Baty International, West Sussex, UK)); Body composition/muscle mass } \\
\text { (bio-impedance analysis) }\end{array}$ & $\mathrm{M} / \mathrm{T}$ \\
\hline & Blood pressure & Omron 705CP II & $\mathrm{M} / \mathrm{T}$ \\
\hline & Physical fitness & $\begin{array}{l}\text { 2-Minute-Step; Chair stand; Contralateral concurrent matching task; } 30-\mathrm{s} \text { Arm Curl Test; Six-Minute Walk Test; } \\
\text { Stair-Climb-Power-Test; Counter Movement Jump; Hand grip; Stick fall test; Timed up and Go; Elderly Fall } \\
\text { Screening Test (EFST) [63]; De Morton Mobility Index (DEMMI) [64]; Four test balance scale [65]; } \\
\text { Keeping balance while walking backwards on a } 3 / 4.5 / 6 \mathrm{~cm} \text { broad beam; Standing as still as possible for } 60 \mathrm{~s} \text {; } \\
\text { Chair Sit and Reach; Back Scratch }\end{array}$ & $\mathrm{M} / \mathrm{T}$ \\
\hline & Activities of daily living & Instrumental activities of daily living (iADL) [66] & SFQ \\
\hline & Quality of life & Satisfaction With Life Scale (SWLS) [67]; Short Form-36 Health Survey (SF-36) [68] & SFQ \\
\hline & Physical Activity & & \\
\hline & Subjective physical activity & International Physical Activity Questionnaire (IPAQ) [69] & SFQ \\
\hline & Objective physical activity & Accelerometer (ActiGraph (ActiGraph, Pensacola, FL, USA)); Fitbit@ (Fitbit Inc., San Francisco, CA, USA) & $\mathrm{M} / \mathrm{T}$ \\
\hline & Health-related behaviour & & \\
\hline & Dietary habits (fruit/vegetable intake) & Self-developed questionnaire & SFQ \\
\hline & Smoking & Adapted from German Health Interview and Examination Survey for Adults (DEGS) & SFQ \\
\hline & Alcohol consumption & Alcohol Use Disorders Identification Test (AUDIT-C) [70] & SFQ \\
\hline & Mental health and personality & & \\
\hline & Personality & Big Five (NEO-FFI), adapted from the European Social Survey 2.1 & SFQ \\
\hline & Depression & Center for Epidemiological Studies Depression Scale (CES-D) [71] & SFQ \\
\hline & Cognitive tests & Auditory Verbal Learning Test (AVLT) [72]; Flanker test [73]; Random number generation task & $\mathrm{M} / \mathrm{T}$ \\
\hline & Self-perception, intention, planning & & \\
\hline & Self-description & Physical Self-Description Questionnaire (PSDQ) [74] & SFQ \\
\hline & Subjective need and demand & Adapted from German Ageing Survey (DEAS) & SFQ \\
\hline & Fear of falls & Geriatric Fear of Falling Measure (GFFM) [75] & SFQ \\
\hline & Health behaviour & Self-developed questionnaire & SFQ \\
\hline & Self-efficacy expectation & Self-developed questionnaire adapted from the Health Action Process (HAPA) model & SFQ \\
\hline & Risk perception & Adapted from Berlin Risk Appraisal and Health Motivation Study (BRAHMS) & SFQ \\
\hline
\end{tabular}


Table 2. Cont.

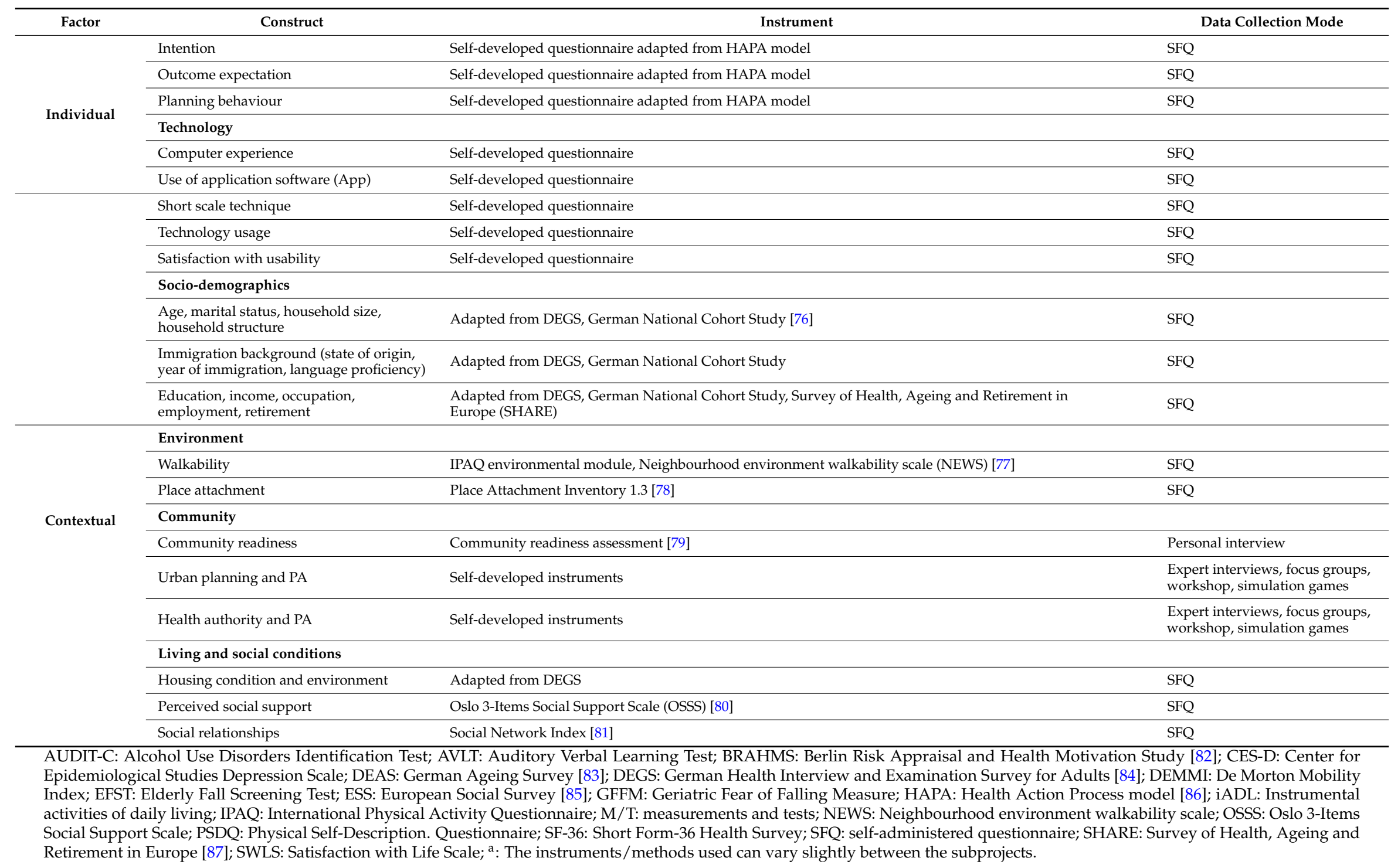


Physical fitness assessments comprise aerobic fitness tests, grip strength, reactivity, agility, balance and postural control and flexibility tests. In several subprojects, both self-reported and objectively measured PA data are collected (Table 2).

Variables covering technological aspects are measured in three subprojects (PROMOTE, OUTDOOR ACTIVE, TECHNOLOGY). Technological factors comprise computer experience, usage and usability of, as well as satisfaction with apps, websites and technology in general. Where feasible, the applicability of the devices and their performance for diagnostic and prevention purposes are assessed. Within the intervention, assistance by technical devices, apps and websites as well as usability and satisfaction are assessed via self-developed questionnaires. Because these variables are influenced by multiple factors such as openness, user acceptance and subjective rating, they are classified under individual characteristics. This appears appropriate because the potential for being shaped by social influences and trends is moderated by personal traits.

\subsubsection{Contextual Factors}

All subprojects collect data on contextual factors such as environmental factors, community situation and living and social conditions from different perspectives. For example, while RTC and AFOOT [61,62] analyse these variables under the focus of community regulations and local government, PROMOTE and OUTDOOR ACTIVE focus on the role of environmental factors (walkability) for PA promotion and maintenance. Functional capacities relevant to daily life activities such as the need for social support, ability to have social activities and relationships, as well as factors such as housing conditions and environment, place attachment and neighbourhood are assessed by standardised self-administered questionnaires (Table 2).

\subsubsection{Inequality}

Socioeconomic characteristics are assessed at individual and community level. Data on gender, immigration background, education, income and employment are collected within the sub-projects. Inequality may also play a role in the analysis of urban and transport planning regulations and applications, and is assessed through interviews with experts and stakeholders in the respective subprojects.

\section{Preliminary Results}

The AEQUIPA project started in 2015. The final results will be available in 2018. So far, the network has achieved a strong regional linkage with communities, local stakeholders and individuals.

Broad assessments of community readiness for change towards improved PA of the elderly have been conducted (RTC subproject) and the information was used to prepare and implement the PROMOTE trial. In the trial, IT-based approaches to support PA behavior change in the target population were investigated. Within RTC, 118 semi-structured interviews with key informants from 23 municipalities, such as persons from public authorities, community centers, elderly advisory boards, or sports clubs, were conducted. Among communities with low Community Readiness score, local stakeholders were contacted and working groups were installed. The willingness and preparedness to engage among the intervention municipalities differed. For example, in one community an existing working group incorporated the topic of PA promotion into their permanent agenda. In another community, stakeholders decided not to form a working group after a first meeting.

In PROMOTE the effects of an IT-based intervention for PA promotion compared to a waiting list control group was examined. So far 168 persons participated in the first wave of data collection that occurred between May and September 2016. The median age of the participants was 70 years. $55.7 \%$ of the participants were female. A second wave started in January 2017 and will end in October 2017. Analyses of intervention effectiveness are planned for the end of 2017.

In the OUTDOOR ACTIVE trial 916 participants were included in the initial survey and the subsequent theory-based development of appropriate community-based interventions. The median 
age of the participants was 70 years. $51.1 \%$ of the participants were female. The data gives insight into the interplay between individual factors, perceived and objective environmental factors and PA. In 2017, the data will be enriched by follow-up data, and thus become a valuable resource for further analyses. Qualitative and quantitative data are being analyzed in the subproject to identify risk profiles for low PA, and also to gain information on how to approach this age group for PA intervention (e.g., barriers and drivers, communication channels, psychological and social profiles).

Individual behavior is the main focus of the TECHNOLOGY subproject which investigates very early preventive interventions to act on pre-frailty, including new IT technologies. 250 participants were included during the first two assessments in 2016. The median age of the participants was 75 years. $59.0 \%$ of the participants were female. A third assessment will take place between July and December 2017 and data analyses will follow.

In the AFOOT study extensive work was done to understand planning processes and entry points for health and equity assessment in selected communities so that administrative processes and structures that support primary prevention are strengthened and adapted.

Realizing the potential of all primary prevention interventions to affect equity in health, training and design support focusing on equitable ways of participant recruitment as well as on assessment of social status among participants are offered across all projects. This was done under the guidance of the EQUAL subproject and aimed to offer an empirical basis for health equity assessment. Findings of an EQUAL lead literature review suggest that many studies on universal interventions to promote PA among older adults have not exploited the potential for assessing equity impacts [88].

\section{Discussion}

PA is an important contributor to healthy ageing. Increasing the proportion of healthy and active, independently living older people is not only a way to reduce the pressure on social and welfare systems, but also an overall goal of modern liveable societies. To achieve these goals, evidence-based age-specific PA interventions that, in addition to individual characteristics, also take contextual and technological factors as well as the impact of intervention on inequality into account, are needed. The work of the AEQUIPA network is expected to provide new knowledge on effective primary prevention through the better understanding of mechanisms and improved promotion of PA in the continuously growing group of older adults. It will also provide new insights into the targeting and tailoring of interventions and will extensively test the application of participatory models of intervention development and implementation. AEQUIPA thus addresses central paradigms of prevention and health promotion and explicitly uses theory guidance to develop and implement PA interventions. The aim is to better understand, and thus be able to act upon, social stratification in access to and uptake of PA interventions by an ageing population.

Our research will also investigate the potential role of innovations such as new communication and measurement technologies. New technological developments e.g., activity trackers or sport watches, might foster PA. The potential role of the said innovations will be analysed for its usability in prevention of inactivity and physical degeneration within AEQUIPA. Interventions that are based on or supported by technology will be developed, tailored and tested to strengthen the critical evidence base on new programs planning to incorporate such tools to support PA. Based on the evidence generated through AEQUIPA, we hope to better understand if and how the use of technological innovations among older adults differs from younger persons. For example, focus on benefits rather than costs have been reported for elderly [89]. In addition, the difference in use of technology between men and women is of interest should technology be used as a prevention tool. Further, the role, design and usability of assistive technology can be taken into account and evaluated in the interventional and user context [90]. However, beyond these aspects of technological innovations in PA related preventions among older adults, users' behaviour plays an important role for all interventions and offers supported by technological products [91]. 
As a further innovative feature, an integrated approach of public health and urban planning is included in the network. This cooperation will help to identify and improve characteristics of the built environment relevant to PA. This approach considers the perspectives of local stakeholders of spatial planning and administrative action to enable sustainable implementation within the region. Further, AEQUIPA allows a comparison of urban and rural regions in two federal states. A guide for intersectoral policy actions will be developed as intervention measure taking the institutional and administrative framework of urban planning and public health as well as limited communal financial resources into account [61].

AEQUIPA researchers are aware that the question of "fun and enjoy" of PA interventions is important for the sustainability of PA, although it is still under-researched. This aspect is not well captured in AEQUIPA as well and should play a greater role in further studies. We are also aware that the wealth of instruments applied in the different studies is extensive and may work against high-spirited voluntary participation and act more as deterrent. Furthermore, the role of PA occurring daily and in less concrete and focused manners is not well captured in the AEQUIPA research program. While within PROMOTE an exercise program was developed, exercises which can be incorporated in the daily routine are not involved; e.g., storing coffee on the upmost kitchen shelf while having the corresponding filters on the lowest shelf to train balance, muscle strength, and balance during ones daily routine. While inequality effects of interventions are studied within the network, the developed concepts and methodological approaches need to be tested and evaluated further and in other contexts.

The results of the intervention evaluation will add to the discourse on intervention design, particularly on how to tailor interventions to the specific needs of older people. However, disabled people and special groups are underrepresented in our work and hence should be considered in future studies.

The ambitious quantitative design of the network and the multifaceted intervention design could lead to a low response rate with a subsequent adverse impact on the evaluability of effects. It is possible that the planned sample sizes within the subprojects will not be reached. The recruitment covers people older than 65 years and particularly focuses on minorities and marginalized groups (low socioeconomic status (SES) - low level of education and occupational prestige), persons with migrant background, no/low PA level which can often not be easily reached; e.g., not responding to participation invitation particularly when written, are not active and generally not interested, have a different cultural understanding. Several measures were taken to facilitate participant recruitment and retention. Community stakeholders and local minority group organizations were approached during the recruitment process. However, the participation among certain groups, e.g., migrants remained low. To stay in touch with the included participants, public events were organized where the progress of the studies were presented (TECHNOLOGY, OUTDOOR ACTIVE). In the PROMOTE intervention study, regular group sessions are provided to increase participant retention. Furthermore, a hotline was installed to provide assistance to study participants in case of technical problems. Nevertheless, our first experiences call for a systematic reflection of these problems. As a consequence, more intensive community participation and a further tailoring of the developed interventions are planned for the next phase of this project. Additionally, despite the fact that it has a sound theoretical foundation and evidence-base, the intervention design might be too complex.

\section{Conclusions}

All in all, the research results foreseen to be generated in this network will directly address national and international health targets for healthy ageing. The research outcomes are also of key relevance to the strengthening of the prevention in the health care system as they will contribute to an evidence-based development and selection of intervention strategies for PA for older adults. The AEQUIPA project started in 2015 and has now completed its second year. The final results will be available in 2018. 
Acknowledgments: The study is funded by the German Federal Ministry of Education and Research (BMBF) (Project No. 01EL1422A-I). The publication of this article was funded by the Open Access Fund of the Leibniz Association. We would like thank the entire AEQUIPA Consortium (Leibniz Institute for Prevention Research and Epidemiology-BIPS, Achterstraße 30, 28359 Bremen, Germany (Tilman Brand, Sarah Forberger, Dirk Gansefort, Saskia Müllmann, Claudia Pischke, Maike Wolters, Hajo Zeeb); University of Bremen, Institute for Public Health und Nursing Research (IPP), Grazer Straße 4, 28359 Bremen, Germany; Department of Social Epidemiology (Gabriele Bolte, Tanja Brüchert, Gesa Lehne); Working Group Epidemiology of Demographic Change (Karin Bammann, Lena Lübs, Jenny Peplies); Department of Qualification and Curriculum Research (Ingrid Darmann-Finck); SOCIUM (Heinz Rothgang); Chemnitz University of Technology, Institute of Human Movement Science and Health, Faculty of Behavioral and Social Sciences, Thüringer Weg 11, 09126 Chemnitz, Germany (Inna Bragina, Claudia Voelcker-Rehage); OFFIS-Institute for Information Technology, Escherweg 2, 26121 Oldenburg, Germany (Jochen Meyer, Jochen Schnauber); Jacobs University Bremen, Department of Psychology and Methods, Campus Ring 1, 28759 Bremen, Germany (Sonia Lippke, Eric Rost); Carl von Ossietzky University of Oldenburg, Ammerländer Heerstrasse 114-118, 26129 Oldenburg, Germany; Department of Computing Science (Susanne Boll); Department of Geriatric Medicine (Jürgen M. Bauer, Lena Dasenbrock); Department of Health Services Research, School of Medicine and Health Sciences (Sebastian Fudickar, Andreas Hein, Andrea Heinks, Sandra Hellmers); Jade University of Applied Sciences Oldenburg, Section Technology and Health for Humans, Ofener Straße 16/19, 26121 Oldenburg, Germany (Frauke Koppelin, Merle Toborg); Dortmund University of Technology, Faculty of Spatial Planning, Department of Urban and Regional Planning (SRP), August-Schmidt-Straße 10, 44227 Dortmund, (S Baumgart, Paula Quentin); Gesundheitswirtschaft Nordwest e. V., Hinter dem Schütting 8, 28195 Bremen, Germany (Sabine Röseler, Tobias Ubert)) for their help.

Author Contributions: Karin Bammann, Jürgen Bauer, Susanne Boll, Gabriele Bolte, Tilman Brand, Andreas Hein, Frauke Koppelin, Sonia Lippke, Jochen Meyer, Claudia R. Pischke, Claudia Voelcker-Rehage, HZ have designed the study and supervised data collection. Sarah Forberger, Tilman Brand, Hajo Zeeb have interpreted the data and drafted the first version of the paper. Sarah Forberger, Karin Bammann, Jürgen Bauer, Susanne Boll, Gabriele Bolte, Tilman Brand, Andreas Hein, Frauke Koppelin, Sonia Lippke, Jochen Meyer, Claudia R. Pischke, Claudia Voelcker-Rehage, Hajo Zeeb have revised and approved the paper.

Conflicts of Interest: The authors declare no conflict of interest. The founding sponsors had no role in the design of the study; in the collection, analyses, or interpretation of data; in the writing of the manuscript, and in the decision to publish the results.

\section{References}

1. Mamolo, M.; Scherbov, S. Population Projections for Forty-Four European Countries: The Ongoing Population Ageing; Vienna Institute of Demography, Austrian Academy of Sciences: Vienna, Austria, 2009.

2. European Commission. The 2015 Ageing Report. Underlying Assumptions and Projection Methodologies; Joint Report Prepared by the European Commission (dg ecfin) and the Economic Policy Committee (awg); European Commission: Brussels, Belgium, 2014.

3. Warburton, D.E.R.; Nicol, C.W.; Bredin, S.S.D. Health benefits of physical activity: The evidence. Can. Med. Assoc. J. 2006, 174, 801-809. [CrossRef] [PubMed]

4. Lee, I.-M.; Shiroma, E.J.; Lobelo, F.; Puska, P.; Blair, S.N.; Katzmarzyk, P.T.; Lancet Physical Activity Serials Working Group. Effect of physical inactivity on major non-communicable diseases worldwide: An analysis of burden of disease and life expectancy. Lancet 2012, 380, 219-229. [CrossRef]

5. World Health Organization. Global Recommendations on Physical Activity for Health. Available online: http://www.who.int/dietphysicalactivity/factsheet_recommendations/en/ (accessed on 26 August 2015).

6. Nelson, M.E.; Rejeski, W.J.; Blair, S.N.; Duncan, P.W.; Judge, J.O.; King, A.C.; Macera, C.A.; Castaneda-Sceppa, C. Physical activity and public health in older adults: Recommendation from the American College of Sports Medicine and the American Heart Association. Circulation 2007, 116, 1094-1105. [CrossRef] [PubMed]

7. Kumar, A.; Delbaere, K.; Zijlstra, G.; Carpenter, H.; Iliffe, S.; Masud, T.; Skelton, D.; Morris, R.; Kendrick, D. Exercise for reducing fear of falling in older people living in the community: Cochrane systematic review and meta-analysis. Age Ageing 2016, 45, 345-352. [CrossRef] [PubMed]

8. Miyashita, M.; Park, J.H.; Takahashi, M.; Suzuki, K.; Stensel, D.; Nakamura, Y. Postprandial lipaemia: Effects of sitting, standing and walking in healthy normolipidaemic humans. Int. J. Sports Med. 2013, 34, $21-27$. [CrossRef] [PubMed]

9. Miyashita, M.; Burns, S.F.; Stensel, D.J. Accumulating short bouts of brisk walking reduces postprandial plasma triacylglycerol concentrations and resting blood pressure in healthy young men. Am. J. Clin. Nutr. 2008, 88, 1225-1231. [PubMed] 
10. Lunde, M.S.H.; Hjellset, V.T.; Hostmark, A.T. Slow post meal walking reduces the blood glucose response: An exploratory study in female Pakistani immigrants. J. Immigr. Minor. Health 2012, 14, 816-822. [CrossRef] [PubMed]

11. Sluik, D.; Buijsse, B.; Muckelbauer, R.; Kaaks, R.; Teucher, B.; Johnsen, N.F.; Tjonneland, A.; Overvad, K.; Ostergaard, J.N.; Amiano, P.; et al. Physical activity and mortality in individuals with diabetes mellitus: A prospective study and meta-analysis. Arch. Intern. Med. 2012, 172, 1285-1295. [CrossRef] [PubMed]

12. Hillman, C.H.; Erickson, K.I.; Kramer, A.F. Be smart, exercise your heart: Exercise effects on brain and cognition. Nat. Rev. Neurosci. 2008, 9, 58-65. [CrossRef] [PubMed]

13. Leveille, S.G. Musculoskeletal aging. Curr. Opin. Rheumatol. 2004, 16, 114-118. [CrossRef] [PubMed]

14. Wolff, E.; Gaudlitz, K.; von Lindenberger, B.-L.; Plag, J.; Heinz, A.; Ströhle, A. Exercise and physical activity in mental disorders. Eur. Arch. Psychiatry Clin. Neurosc. 2011, 261, 186-191. [CrossRef] [PubMed]

15. Kortebein, P.; Ferrando, A.; Lombeida, J.; Wolfe, R.; Evans, W.J. Effect of 10 days of bed rest on skeletal muscle in healthy older adults. JAMA 2007, 297, 1769-1774. [CrossRef] [PubMed]

16. Naci, H.; Ioannidis, J.P.A. Comparative effectiveness of exercise and drug interventions on mortality outcomes: Metaepidemiological study. Br. Med. J. 2013, 347, 14. [CrossRef] [PubMed]

17. Krug, S.; Jordan, S.; Mensink, G.; Müters, S.; Finger, J.; Lampert, T. Physical activity: Results of the German Health Interview and Examination Survey for Adults (DEGS1). Bundesgesundheitsblatt Gesundheitsforschung Gesundheitsschutz 2013, 56, 765-771. [CrossRef] [PubMed]

18. Kobayashi, L.C.; Wardle, J.; von Wagner, C. Internet use, social engagement and health literacy decline during ageing in a longitudinal cohort of older English adults. J. Epidemiol. Community Health 2015, 69, 278-283. [CrossRef] [PubMed]

19. Hirvensalo, M.; Lintunen, T. Life-course perspective for physical activity and sports participation. Eur. Rev. Aging Phys. Act. 2011, 8, 13-22. [CrossRef]

20. Ko, S.-U.; Hausdorff, J.M.; Ferrucci, L. Age-associated differences in the gait pattern changes of older adults during fast-speed and fatigue conditions: Results from the Baltimore longitudinal study of ageing. Age Ageing 2010, 39, 688-694. [CrossRef] [PubMed]

21. Koster, A.; Visser, M.; Simonsick, E.M.; Yu, B.; Allison, D.B.; Newman, A.B.; van Eijk, J.T.M.; Schwartz, A.V.; Satterfield, S.; Harris, T.B.; et al. Association between fitness and changes in body composition and muscle strength. J. Am. Geriatr. Soc. 2010, 58, 219-226. [CrossRef] [PubMed]

22. Gill, T.M.; Gahbauer, E.A.; Han, L.; Allore, H.G. Trajectories of disability in the last year of life. N. Engl. J. Med. 2010, 362, 1173-1180. [CrossRef] [PubMed]

23. Schwarzer, R.; Lippke, S.; Luszczynska, A. Mechanisms of health behavior change in persons with chronic illness or disability: The Health Action Process Approach (HAPA). Rehabil. Psychol. 2011, 56, 161-170. [CrossRef] [PubMed]

24. Sallis, J.F.; Owen, N.; Fischer, E.B. Ecological models of health behavior. In Health Behavior and Health Education: Theory, Research, and Practice, 4th ed.; Glanz, K., Rimer, B.K., Viswanath, K., Eds.; Jossey-Bass: San Francisco, CA, USA, 2008; pp. 465-486.

25. Noar, S.M.; Benac, C.N.; Harris, M.S. Does tailoring matter? Meta-analytic review of tailored print health behavior change interventions. Psychol. Bull. 2007, 133, 673-693. [CrossRef] [PubMed]

26. Häkkinen, K. Ageing and neuromuscular adaptation to strength training. In Strength and Power in Sport; Wiley: Hoboken, NJ, USA, 2008; Volume 600, p. 409.

27. Lippke, S.; Ziegelmann, J.P. Theory-based health behavior change: Developing, testing, and applying theories for evidence-based interventions. Appl. Psychol. 2008, 57, 698-716. [CrossRef]

28. Hammarström, A.; Johansson, K.; Annandale, E.; Ahlgren, C.; Aléx, L.; Christianson, M.; Elwér, S.; Eriksson, C.; Fjellman-Wiklund, A.; Gilenstam, K. Central gender theoretical concepts in health research: The state of the art. J. Epidemiol. Community Health 2014, 68, 185-190. [CrossRef] [PubMed]

29. Stith, S.; Pruitt, I.; Dees, J.; Fronce, M.; Green, N.; Som, A.; Linkh, D. Implementing community-based prevention programming: A review of the literature. J. Prim. Prev. 2006, 27, 599-617. [CrossRef] [PubMed]

30. Green, L.W.; Kreuter, M.W. Health Program Planning: An Educational and Ecological Approach, 4th ed.; McGraw-Hill Education Ltd.: New York, NY, USA, 2005.

31. Yen, I.H.; Michael, Y.L.; Perdue, L. Neighborhood environment in studies of health of older adults: A systematic review. Am. J. Prev. Med. 2009, 37, 455-463. [CrossRef] [PubMed] 
32. Sallis, J.F.; Spoon, C.; Cavill, N.; Engelberg, J.K.; Gebel, K.; Parker, M.; Thornton, C.M.; Lou, D.; Wilson, A.L.; Cutter, C.L. Co-benefits of designing communities for active living: An exploration of literature. Int. J. Behav. Nutr. Phys. Act. 2015, 12. [CrossRef] [PubMed]

33. Burton, E. Streets ahead? The role of the built environment in healthy ageing. Perspect. Public Health 2012, 132, 161-162. [PubMed]

34. Rydin, Y.; Bleahu, A.; Davies, M.; Dávila, J.D.; Friel, S.; De Grandis, G.; Groce, N.; Hallal, P.C.; Hamilton, I.; Howden-Chapman, P. Shaping cities for health: Complexity and the planning of urban environments in the 21st century. Lancet 2012, 379, 2079-2108. [CrossRef]

35. Quigley, R.; Den Broeder, L.; Furu, P.; Bond, A.; Cave, B.; Bos, R. Health impact assessment international best practice principles. In Special Publication Series; International Association for Impact Assessment: San Fransisco, CA, USA, 2006; Volume 5, pp. 1-4.

36. Tucker-Seeley, R.D.; Subramanian, S.V.; Li, Y.; Sorensen, G. Neighborhood safety, socioeconomic status, and physical activity in older adults. Am. J. Prev. Med. 2009, 37, 207-213. [CrossRef] [PubMed]

37. Sallis, J.F.; Floyd, M.F.; Rodriguez, D.A.; Saelens, B.E. Role of built environments in physical activity, obesity, and cardiovascular disease. Circulation 2012, 125, 729-737. [CrossRef] [PubMed]

38. Fanning, J.; Mullen, S.P.; McAuley, E. Increasing physical activity with mobile devices: A meta-analysis. J. Med. Internet Res. 2012, 14, e161. [CrossRef] [PubMed]

39. European Commission. Communication from the Commission to the European Parliament, the Council, the European Economic and Social Committee and the Committee of the Regions; Ehealth Action Plan 2012-2020-Innovative Healthcare for the 21st Century; European Commission: Brussels, Belgium, 2012.

40. Dietzel, G.T. E-health und Gesundheitstelematik-Herausforderungen und Chancen. Dtsch. Arztebl. 2001, 98, 158-160. (In German).

41. King, A.C.; Ahn, D.K.; Oliveira, B.M.; Atienza, A.A.; Castro, C.M.; Gardner, C.D. Promoting physical activity through hand-held computer technology. Am. J. Prev. Med. 2008, 34, 138-142. [CrossRef] [PubMed]

42. Meyer, J.; Boll, S. Smart health systems for personal health action plans. In Proceedings of the 2014 IEEE 16th International Conference on E-Health Networking, Applications and Services (Healthcom), Natal, Brazil, 15-18 October 2014; pp. 404-410.

43. Klasnja, P.; Pratt, W. Healthcare in the pocket: Mapping the space of mobile-phone health interventions. J. Biomed. Inform. 2012, 45, 184-198. [CrossRef] [PubMed]

44. Hayes, G.R. Interactive systems for health. Interactions 2013, 20, 20-23. [CrossRef]

45. Katzouris, N.; Artikis, A.; Makedon, F.; Karkaletsis, V.; Paliouras, G. Event recognition for assisted independent living. In Proceedings of the 6th International Conference on Pervasive Technologies Related to Assistive Environments, Island of Rhode, Greece, 29-31 May 2013; ACM: New York, NY, USA; p. 26.

46. Schmid, A.; Dörfler, I.; Dany, F.; Böpple, O. Analyse der Akzeptanzkriterien für mobile Anwendungen im Bereich Gesundheit in der Zielgruppe 50+. In Technologiegestützte Dienstleistungsinnovation in der Gesundheitswirtschaft; Shire, K.A., Leimeister, J.M., Eds.; Springer: Berlin, Germany, 2012; pp. 57-82. (In German)

47. Beenackers, M.A.; Kamphuis, C.B.; Giskes, K.; Brug, J.; Kunst, A.E.; Burdorf, A.; van Lenthe, F.J. Socioeconomic inequalities in occupational, leisure-time, and transport related physical activity among european adults: A systematic review. Int. J. Behav. Nutr. Phys. Act. 2012, 9, 116. [CrossRef] [PubMed]

48. Smith, L.; Gardner, B.; Fisher, A.; Hamer, M. Patterns and correlates of physical activity behaviour over 10 years in older adults: Prospective analyses from the English Longitudinal Study of Ageing. BMJ Open 2015, 5. [CrossRef] [PubMed]

49. Hillsdon, M.; Lawlor, D.A.; Ebrahim, S.; Morris, J.N. Physical activity in older women: Associations with area deprivation and with socioeconomic position over the life course: Observations in the british women's heart and health study. J. Epidemiol. Community Health 2008, 62, 344-350. [CrossRef] [PubMed]

50. Sun, F.; Norman, I.J.; While, A.E. Physical activity in older people: A systematic review. BMC Public Health 2013, 13, 449. [CrossRef] [PubMed]

51. Van Stralen, M.M.; De Vries, H.; Mudde, A.N.; Bolman, C.; Lechner, L. Determinants of initiation and maintenance of physical activity among older adults: A literature review. Health Psychol. Rev. 2009, 3, 147-207. [CrossRef] 
52. Murtagh, E.M.; Murphy, M.H.; Murphy, N.M.; Woods, C.; Nevill, A.M.; Lane, A. Prevalence and correlates of physical inactivity in community-dwelling older adults in Ireland. PLoS ONE 2015, 10, e0118293. [CrossRef] [PubMed]

53. Frohlich, K.L.; Potvin, L. Transcending the known in public health practice: The inequality paradox: The population approach and vulnerable populations. Am. J. Public Health 2008, 98, 216-221. [CrossRef] [PubMed]

54. McLaren, L.; McIntyre, L.; Kirkpatrick, S. Rose's population strategy of prevention need not increase social inequalities in health. Int. J. Epidemiol. 2010, 39, 372-377. [CrossRef] [PubMed]

55. Lorenc, T.; Petticrew, M.; Welch, V.; Tugwell, P. What types of interventions generate inequalities? Evidence from systematic reviews. J. Epidemiol. Community Health 2013, 67, 190-193. [CrossRef] [PubMed]

56. Humphreys, D.K.; Ogilvie, D. Synthesising evidence for equity impacts of population-based physical activity interventions: A pilot study. Int. J. Behav. Nutr. Phys. Act. 2013, 10, 76. [CrossRef] [PubMed]

57. Attwood, S.; van Sluijs, E.; Sutton, S. Exploring equity in primary-care-based physical activity interventions using PROGRESS-Plus: A systematic review and evidence synthesis. Int. J. Behav. Nutr. Phys. Act. 2016, 13, 60. [CrossRef] [PubMed]

58. Baxter, S.; Johnson, M.; Payne, N.; Buckley-Woods, H.; Blank, L.; Hock, E.; Daley, A.; Taylor, A.; Pavey, T.; Mountain, G.; et al. Promoting and maintaining physical activity in the transition to retirement: A systematic review of interventions for adults around retirement age. Int. J. Behav. Nutr. Phys. Act. 2016, 13, 12. [CrossRef] [PubMed]

59. Baker, P.R.; Francis, D.P.; Soares, J.; Weightman, A.L.; Foster, C. Community wide interventions for increasing physical activity. Cochrane Database Syst. Rev. 2015, 1. [CrossRef]

60. Thornton, C.M.; Kerr, J.; Conway, T.L.; Saelens, B.E.; Sallis, J.F.; Ahn, D.K.; Frank, L.D.; Cain, K.L.; King, A.C. Physical activity in older adults: An ecological approach. Ann. Behav. Med. 2016, 1-11. [CrossRef] [PubMed]

61. Brüchert, T.; Quentin, P.; Baumgart, S.; Bolte, G. Intersectoral collaboration of public health and urban planning for promotion of mobility and healthy ageing: Protocol of the Afoot Project. Cities Health 2017. [CrossRef]

62. Brand, T.; Gansefort, D.; Rothgang, H.; Röseler, S.; Meyer, J.; Zeeb, H. Promoting community readiness for physical activity among older adults in Germany-Protocol of the ready to change intervention trial. BMC Public Health 2016, 16. [CrossRef] [PubMed]

63. Cwikel, J.G.; Fried, A.V.; Biderman, A.; Galinsky, D. Validation of a fall-risk screening test, the Elderly Fall Screening Test (EFST), for community-dwelling elderly. Disabil. Rehabil. 1998, 20, 161-167. [CrossRef] [PubMed]

64. De Morton, N.A.; Davidson, M.; Keating, J.L. The De Morton Mobility Index (DEMMI): An essential health index for an ageing world. Health Qual. Life Outcomes 2008, 6, 63. [CrossRef] [PubMed]

65. Rossiter-Fornoff, J.E.; Wolf, S.L.; Wolfson, L.I.; Buchner, D.M. A cross-sectional validation study of the FICSIT common data base static balance measures. Frailty and injuries: Cooperative studies of intervention techniques. J. Gerontol. Ser. A Biol. Sci. Med. Sci. 1995, 50, M291-M297. [CrossRef]

66. Lawton, M.P.; Brody, E.M. Assessment of older people: Self-maintaining and instrumental activities of daily living. Gerontologist 1969, 9, 179-186. [CrossRef] [PubMed]

67. Diener, E.; Emmons, R.A.; Larsen, R.J.; Griffin, S. The Satisfaction with Life Scale. J. Personal. Assess. 1985, 49, 71-75. [CrossRef] [PubMed]

68. Jenkinson, C.; Coulter, A.; Wright, L. Short form 36 (SF36) health survey questionnaire: Normative data for adults of working age. Br. Med. J. 1993, 306, 1437-1440. [CrossRef]

69. Booth, M.L.; Ainsworth, B.E.; Pratt, M.; Ekelund, U.; Yngve, A.; Sallis, J.F.; Oja, P. International physical activity questionnaire: 12-country reliability and validity. Med. Sci. Sports Exerc. 2003, 195, 1381-1395.

70. Bush, K.; Kivlahan, D.R.; McDonell, M.B.; Fihn, S.D.; Bradley, K.A. The AUDIT alcohol consumption questions (AUDIT-C): An effective brief screening test for problem drinking. Arch. Intern. Med. 1998, 158, 1789-1795. [CrossRef] [PubMed]

71. Irwin, M.; Artin, K.; Oxman, M.N. Screening for depression in the older adult: Criterion validity of the 10-item center for epidemiological studies depression scale (CES-D). Arch. Intern. Med. 1999, 159, 1701-1704. [CrossRef] [PubMed] 
72. Ivnik, R.J.; Malec, J.F.; Tangalos, E.G.; Petersen, R.C.; Kokmen, E.; Kurland, L.T. The auditory-verbal learning test (AVLT): Norms for ages 55 years and older. Psychol. Assess. J. Consult. Clin. Psychol. 1990, 2, 304-312. [CrossRef]

73. Botvinick, M.; Nystrom, L.E.; Fissell, K.; Carter, C.S.; Cohen, J.D. Conflict monitoring versus selection-for-action in anterior cingulate cortex. Nature 1999, 402, 179-181. [CrossRef] [PubMed]

74. Marsh, H.W.; Richards, G.E.; Johnson, S.; Roche, L.; Tremayne, P. Physical self-description questionnaire: Psychometric properties and a multitrait-multimethod analysis of relations to existing instruments. J. Sport Exerc. Psychol. 1994, 16, 270-305. [CrossRef]

75. Huang, T.-T. Geriatric fear of falling measure: Development and psychometric testing. Int. J. Nurs. Stud. 2006, 43, 357-365. [CrossRef] [PubMed]

76. German National Cohort Study. Available online: www.nako.de (accessed on 31 March 2017).

77. Saelens, B.E.; Sallis, J.F.; Black, J.B.; Chen, D. Neighborhood-based differences in physical activity: An environment scale evaluation. Am. J. Public Health 2003, 93, 1552-1558. [CrossRef] [PubMed]

78. Williams, D.R.; Vaske, J.J. The measurement of place attachment: Validity and generalizability of a psychometric approach. For. Sci. 2003, 49, 830-840.

79. Edwards, R.W.; Jumper-Thurman, P.; Plested, B.A.; Oetting, E.R.; Swanson, L. Community readiness: Research to practice. J. Community Psychol. 2000, 28, 291-307. [CrossRef]

80. Brevik, J.; Dalgard, O. The Health Profile Inventory; University of Oslo: Oslo, Norway, 1996.

81. Berkman, L.F.; Syme, S.L. Social networks, host resistance, and mortality: A nine-year follow-up study of Alameda County residents. Am. J. Epidemiol. 1979, 109, 186-204. [CrossRef] [PubMed]

82. Berlin Risk Appraisal and Health Motivation Study. Available online: http://www.gesundheitsrisiko.de/ brahms.html (accessed on 31 March 2017).

83. German Ageing Survey. Available online: https://www.dza.de/en/research/deas.html (accessed on 31 March 2017).

84. German Health Interview and Examination Survey for Adults. Available online: http://www.degs-studie. de/deutsch/home.html (accessed on 31 March 2017).

85. European Social Survey. Available online: http://www.europeansocialsurvey.org/data/download.html?r=6 (accessed on 31 March 2017).

86. Health Action Process Model. Available online: http://www.hapa-model.de (accessed on 31 March 2017).

87. Survey of Health, Ageing and Retirement in Europe. Available online: http://www.share-project.org/ (accessed on 31 March 2017).

88. Lehne, G.; Bolte, G. Impact of universal interventions on social inequalities in physical activity among older adults: An equity-focused systematic review. Int. J. Behav. Nutr. Phys. Act. 2017, 14, 20. [CrossRef] [PubMed]

89. Melenhorst, A.S.; Rogers, W.A.; Bouwhuis, D.G. Older adults' motivated choice for technological innovation: Evidence for benefit-driven selectivity. Psychol. Aging 2006, 21, 190-195. [CrossRef] [PubMed]

90. Lindenberger, U.; Lovden, M.; Schellenbach, M.; Li, S.C.; Kruger, A. Psychological principles of successful aging technologies: A mini-review. Gerontology 2008, 54, 59-68. [CrossRef] [PubMed]

91. Barnard, Y.; Bradley, M.D.; Hodgson, F.; Lloyd, A.D. Learning to use new technologies by older adults: Perceived difficulties, experimentation behaviour and usability. Comput. Hum. Behav. 2013, 29, 1715-1724. [CrossRef]

(C) 2017 by the authors. Licensee MDPI, Basel, Switzerland. This article is an open access article distributed under the terms and conditions of the Creative Commons Attribution (CC BY) license (http:/ / creativecommons.org/licenses/by/4.0/). 